square kilometre. If, however, we take account, as we are bound to do, of the difference of direction, treating those which fluw upwards as positive and those which flow down as negative, the result would show that the mean current in the United Kingdom is about five-thousandths of an ampere per square kilometre. Of course, if we deal with considerable but smaller areas, the precise value obtained depends upon the district chosen, but this does not affect the conclusion to any importan extent. Thus, for the reason I have already given, it is probable that our knowledge of the magnetic state of the central districts is better than our information as to the borders, and if we confine ourselves to the centre of the kingdom, we find that the average current is downwards in both cases, and that in I886 it was apparently a little larger, and in I89I a little less than one-hundredth of an ampere per square kilometre.

Even these concordant conclusions are rendered more doubt. ful if the two completely independent sets of results obtained by means of the two surveys for 1886 to I $89 \mathrm{I}$, respectively, are reduced to the same date. It is true that the magnitudes of the calculated currents are larger than those shown in the map given above, but on the whole they are so opposed in direction that the comparison compels us to reject the hypothesis of their physical reality.

I therefore feel justified in asserting that no evidence that can be relied up on points to the existence of any flow of electric currents through the surface of the British Isles, whether from below to above or from above to below. The quantities are so minute that if they existed they could barely be measured, and the results are too discordant to command assent.

Since the survey of the United Kingdom was completed, my friend Dr. Van Rijckevorsel has made a minute magnetic survey of Holland. In the case of so small a district it is more difficul to eliminate the effects of local disturbances than when the area to be dealt with is larger, and thus I doubt whether conclusions as to the flow of electrical currents drawn from Holland alone could be regarded as trustworthy. Taking them, however, for what they are worth, they indicate an upward current of about one-tenth of an ampere per square kilometre for that country. All these quantities are less than the currents which Dr. Schmidt's calculations demand. In the neighbourhood of the United Kingdom the flow should, according to his calculations, be upwards and the magnitude about fifteen-hundredths of an ampere per square kilometre. This is approached by the flow in Holland, but is from ten to wenty times greater than the average obtained over large areas in the United Kingdom.

So far, then, the question as to whether such currents really exist appears to be doubtful. The calculations of Schmidt and Bauer lead to the conclusion that when the world as a whole is investigated the answer is affirmative, but all the more accurate investigations which have hitherto been made in small areas combine to prove either that the currents do not exist, or that they are less than Dr. Schmidt's theory demands. This fact, taken by itself, is not conclusive, as Sweden, the United Kingdom, and Holland are all in the west of Europe, and it might well be that this happened to be a district in which the currents were exceptionally small; but, on the other hand, the doubt thus raised is formidable. Dr. von Bezold has recently stated to the Berlin Academy that Dr. Schmidt himself must now be added to the list of doubters; and von Bezold confirms this caution by figures which lead him to the conclusion that in all probability the results obtained from calculations which embrace the whole globe are due rather to the want of accuracy of our knowledge than of the physical reality of currents from earth to air. I should myself be sorry to pronounce a final opinion, but I must confess that I seriously doubt whether the horizontal magnetic force has been determined with adequate accuracy at a sufficient number of places in the vast regions which are covered with the sea to enable us to draw any final conclusion from areas which include them, and I certainly consider that the balance of evidence is at present opposed to the physical reality of the currents. Before we can accept the opposite proposition some evidence must be produced based on surveys as complete as those of England and Holland. Before long we shall probably have full information as to France and Maryland, and it is possible that one or other of these may furnish positive evidence sufficient to outweigh the negative results which have hitherto been obtained.

(To be continued.)
A PROPOSED SWEDISH EXPEDITION TO THE ARCTIC REGIONS.

A YEAR since, Dr. A. G. Nathorst, of Stockholm, read a paper before the Swedish Society for Anthropology and Geology, entitled “ Återblick på Polarforskningens närvarende Ställning samt Förslag till en Svensk Polarexpedition" (a review of the present position of Polar investigation, with a project for a Swedish Polar expedition), which has since been published in Ymer (Årgång I896, Heft 4, pp. 267-286), the journal of the Society. At the time of reading the paper, there seemed but little probability of a near realisation of the projected scheme; but, during the present year, the King of Sweden and certain wealthy merchants of Stockholm and Gothenburg have generously come forward and provided the funds necessary for carrying it out, and Dr. Nathorst, who will act as the scientific leader of the expedition, is now engaged in preparations for a start next year (1898).

As the result of Nansen's voyage, Dr. Nathorst thinks that there is but little probability of the discovery of fresh land areas in the vicinity of the Pole, and that the aim of future expeditions to the Arctic regions should be a thorough scientific investigation of those lands, of which at present but little is known beyond the fact of their existence. Under this head may be mentioned the west coast of Ellesmere Land and Grinnell Land and the neighbouring islands; also the shores of Jones Sound, in Arctic America. Further, large tracts of the north-eastern and north-western coasts of Greenland remain to be examined, in spite of the admirable work of the Danish. Austrian, and other exploring expeditions. But it is with Spitsbergen and the region east of it that previous Polar explorations on the part of Sweden have been most closely connected; and though no fewer than twelve different Swedish expeditions, led by such men as Torell, Nordenskiöld, Nathorst, de Geer, and others, have visited this region since 1858 , and that it has been the field of work for expeditions from other countries as well, the most recent being that under Sir Martin Conway in 1896 , it yet offers, in Nathorst's opinion, a rich harvest for scientific investigation.

The west coast of Spitsbergen is now fairly well known, but owing to the ice coming from the east and blockading the eastern coasts of the island, nothing has as as yet been ascertained of their geological structure. The same obstacle has also prevented observations on Stans Foreland (Edge Island), Barentz Land, North East Land, Kung Karls Land, and Ny Island; but it is probable, that given favourable conditions of the ice, a steam vessel would be able to approach sufficiently near these islands to allow of their geology at least to be made out. The exploration of these lands between Spitsbergen and Franz Josef Land is the main object of the expedition; but should this be frustrated by the prevalence of the ice, the research work would be carried on in Spitsbergen itself, and more particularly a study would be made of the raised shell-banks and terraces, evidencing a comparatively recent elevation of the land, and of the remarkable quaternary deposits which show that the climate of the island, for a certain interval after the Ice age, was warmer than at the present time. Promising botanical results might be also expected from an examination of the valleys extending from the heads of the fiords, as, for example, those in Sassen Bay, Kol Bay, and Van Mijens Bay.

A stout vessel of from 350 to 400 tons, and a crew of thirteen men, would, in Nathorst's opinion, be most suitable for the undertaking; and the scientific staff would consist of a geologist, a botanist, two zoologists, one hydrographer and meteorologist, and one for cartography and photography. It is not intended to over-winter in the Arctic regions, but the vessel would be provisioned for a year, in case of accidents. The estimated cost of the expedition is about $4000 \%$. It is proposed to reach Spitsbergen in the beginning of June, and work there until the middle of August, when it is hoped the ice will allow Kung Karls Land and the olher islands near it to be examined.

\section{THE USE OF KITES IN WEATHER PREDICTION.}

THE systematic exploration of the upper air by means of kites is referred to by Prof. Cleveland Abbe in the Monthly Weather leview, at the end of a long article upon the experiments made previous to 1893 . It is pointed out that at that time the Malay kite and the free balloon were merely 
looked upon as the means (loccas onally obtaining isolated items of information from the upper regions; the world had not then awakened to the possibility of the work inaugurated by Prof. Moore in July I895, which looks to the compilation of a daily map of simultaneous observations high above the earth's surface and over a large portion of the United States, for study in connection with the map of surface conditions. Observations of the air at a single station can have but little value compared with the international balloon work of Europe, or the extended national kite work of the U.S. Weather Bureau.

In an address at Toronto, before the British Association, Prof. Moore is reported by the Review to have said :

"For twenty-seven years the forecasters of the Weather Bureau have studied the inception, development, and progression of these different classes of atmospheric disturbances. From a knowledge personally gained by many years' service as an official forecaster, I do not hesitate to express the opinion that we have long since reached the highest degree of accuracy in the making of forecasts possible to be attained with surface readings. It is patent that we are extremely ignorant of the mechanics of the storm; of the operations of those vast yet subtle forces in free air which give inception to the disturbance, and which supply the energy necessary to continue the same. Long having realised this, I determined at once, on coming to the control of the United States Weather Bureau, to systematically attack the problem of upper-air exploration, with the hope ultimately of being able to construct a daily synoptic weather chart from simultaneous readings taken in free air at an altitude of not less than one mile above the earth. It appeared to me that all previous plans for investigating the upper air, by means of free and uncontrollable balloons, by observers in balloons, or by isolated kite stations or mountain observatories, were of little value in getting the information absolutely necessary to the improvement of our methods of forecasting. Simultaneous observations, at a uniform high level, from many co-operating kite stations, was the fundamental feature of the plan that is inaugurated for the prosecution of this important investigation.

"Prof. Marvin was assigned to the difficult task of devising appliances and making instruments, and I am pleased to say that we have improved on kite flying to such an extent that apparatus is now easily sent up to a height of one mile in only a moderate wind. We have made an automatic instrument that, while weighing less than two pounds, will record temperature, pressure, humidity, and wind velocity. By January next we expect to have not less than twenty stations placed between the Rocky Mountains and the Atlantic Ocean taking daily readings at an elevation of one mile or more.

"We shall then construct a chart from the high-level readings obtained at these twenty stations, and study the same in connection with the surface chart made at the same moment. As we shall thus be able to map out not only, as now, the horizontal gradients for the lower surface conditions, but in addition the simultaneous gradients for the upper level, and, what is of still more importance, shall be able to deduce from these, for any section of the atmosphere, the simultaneous vertical gradients of temperature, humidity, pressure, and wind velocity, we may confidently hope to better understand the development of storms and cold waves, and eventually improve the forecasts of their future course, extent, and rate of movement. It will be a fascinating study to note the progress of cold waves at the upper and lower levels, and to determine whether the changes in temperature do not first begin above. I am anxious to know the difterence in temperature between the surface and the upper strat um in the four quadrants of the cyclone, and also of the anticyclone, especially when the storm or cold-wave conditions are intense. The vertical distribution of temperature in the several quadrants may give a clue to the future direction of movement of the disturbance."

\section{UNIVERSITY AND EDUCATIONAL INTELLIGENCE.}

Miss Emily Penrose, principal of Bedford College, London, has been appointed principal of the Royal Holloway College, Egham.

Mr. WM. H. SAGE and Dean Sage have presented to Cornell University the large residence of the late Mr. Henry W. Sage, at Ithaca, for a students' hospital, and will equip it and endow it with 100,000 dols. The residence is valued at 80,000 dols.
THE following resolution has been unanimously passed by the lecturers and teachers in the medical school of Guy's Hospital : " That the medical school of Guy's Hospital earnestly request Her Majesty's Government to reintroduce into Parliament the London University Commission Bill of 1897 , and to pass it into law during the ensuing Session."

AMONG the institutions created during the last half-century for the promotion of scientific research and education, the Sheffield Scientific School of Yale College, New Haven, holds an honourable place. A review of the foundation of the School, and of the work of the distinguished investigators who have been connected with it, was given in a discourse delivered by President Gilman at the semi-centennial anniversary recently held. It was in 1847 that Profs. Silliman and Norton opened a laboratory on the College grounds for the purpose of practical instruction in the applications of science to the arts and agriculture. Thus was born the Sheffield Scientific School of Yale University. At first chemistry was alone; engineering soon found a place ; mathematics, physics and astronomy joined the oligarchy; in due time, mineralogy, geology, physical geography, zoology, botany and physiology found a welcome; modern languages and literature, history and economics, became strong allies. While this evolution was going on, not a word was spoken in disparagement of classical culture, nor a word of religious controversy. From the beginning onwards the institution has been the department of a University which never suffered its love of letters to blind its eyes to the value of science. The School largely owes its success to its association with the fame, the fortune, and the followers of a great alma mater. Substantial advantages were bestowed by the mother upon her offspring; and the present high position which the School occupies shows that the child has deserved the encouragement it has received.

A MEETING was held at the University of London on Tuesday afternoon, the Chancellor (Lord Herschell) presiding, to discuss the proposed legislation on the University of London question. The Times reports that there were present, besides the ViceChancellor (Sir Henry Roscoe), representatives of the Corporation of the City, the Technical Education Board of the London County Council, the Royal Colleges of Physicians and Surgeons, the various medical schools, University College, King's College, Bedford College, the Royal College of Science, and the City and Guilds of London Institute. The Chancellor invited expression of opinion on the London University Commission Bill which the Government propose to reintroduce early in the Session. He said that the Bill embodied the compromise between the various parties hitherto in conflict, and that it was to receive the support of the Senate, as also of both parties in Convocation. The Chancellor further explained why no proposal for any new charter was within the range of practical politics, reconstitution at the hands of a statutory commission being the only remaining course. He therefore urged the acceptance of the compromise. Many of those present spoke in favour of the scheme, and urged that a deputation should wait upon the Vice-President of Council at an early date. The only objection came from one of the smaller medical schools, which declared its preference for the creation of a second University in London. The feeling of the conference was, however, entirely in favour of the reconstruction of the existing University. A deputation to the Government will be appointed as suggested to urge the passing of the Bill.

\section{SCIENTIFIC SERIALS.}

Butietin of the American Mathematical Society, November I 897.- The number opens with an account, by Prof. Osgood, of the proceedings at the International Congress of Mathematicians held at Ziirich in August last. The transactions of the Congress, which was attended by about two hundred mathematicians, 10. gether with the papers read, or presented, are to be published in full.-Prof. J. McMahon performs a like work for the Detroit meeting of the American Association for the Advancement of Science. An analysis of the twenty-one papers presented to the Section is given. One of these communications was an account of stereoscopic views of spherical catenaries and gyroscopic curves by Prof. Greenhill, who was present at the meeting, and to whom the Section " is also indebted for instructive remarks made in connection with many of the other papers." Then follow five papers read before the American Mathematical

NO. I 468, vOL. 57] 